\title{
THERMOGRAVIMETRIC ANALYSIS OF SACCHARUM/UNSATURATED POLYESTER COMPOSITES
}

\author{
Aseel Mahmmod Abdulah \\ Department of Materials Engineering - University of Technology, Iraq - Baghdad \\ Email:aseelmahmood4@gmai.com \\ Nadia Aziz, \\ Department of Materials Engineering - University of Technology, Iraq-Baghdad. \\ E mail:Chemistforever3@gmail.com
}

\begin{abstract}
The investigation on the thermogravimetric analysis of unsaturated polyester matrix composites reinforced with untreated saccharum fibers and other treated by alkaline solution of $\mathrm{NaOH}$ with four weight percent include $0.5,1,2$ and $2.5 \%$ was involved in this work. Generally the incorporation of saccharum fibers slightly change the thermal stability of the unsaturated polyester matrix by the weight loss value and only for reinforcement by unsaturated sacchrum fibers and that treated in $2.5 \% \mathrm{NaOH}$.
\end{abstract}

Keywords: Unsaturated polyester composites; Thermogavimertic behavior; TG curve

\section{INTRODUCTION}

Saccharum (Sugarcane) is composed of $42 \%$ of cellulose, $25 \%$ hemicellulose and $20 \%$ lignin [1], hemicellulose consists of number of saccharides that be amorphous in their structure and rich in their branchs. A long unbranched glucose polymer refers to cellulose with a strong and ordered structure, in addition to have a high thermal stability. While an aromatic rings with many branches refers to lignin which may be degraded in a broad range of temperatures [2]. The degree of crystallinity of sugarcane fibers depends on the amount of hemicellulose and lignin so to increase crystalinity of sugar cane fibers it must be treated with alkali solution in order to dissolve hemicellulose and lignin leaving highly ordered chains of cellulose [3]. Natural fibers have been used in a wide range to reinforce polymeric composites because of their eco-friendly nature.

This present research aims to study the thermogravimeteric analysis unsaturated polyester composites reinforced with Saccharum short fibers. The Saccharum fibers were chemical treated with five concentrations of $\mathrm{NaOH}(0.5,1,2$ and $2.5 \mathrm{M})$ to investigate the effect of treated fibers on the thermal analysis of the prepared composites.

\section{EXPERIMENTAL PART}

The used matrix system in the present study is the unsaturated polyester which representing thermosetting polymer. This polymer is thermosets type of polymers. To prepare polymer matrix, 2 gm of hardener was added to each $100 \mathrm{gm}$ of unsaturated polyester. 


\section{AL-QADISIYAH JOURNAL FOR ENGINEERING SCIENCES}

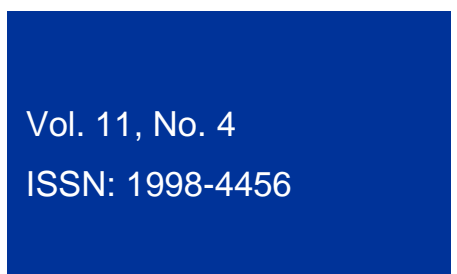

To prepare the composites, many steps were achieved for saccharum fibers including: collection, washing in distilled water and drying in an air oven for $10 \mathrm{~h}$ at $60^{\circ} \mathrm{C}$. These fibers used as short- fibers with $\approx 1 \mathrm{~cm}$ in length. The chemical composition of this fiber was 45.5 cellulose, 27 hemicelluloses, 21.1 lignin, 4.6 extractives and $2.2 \mathrm{wt} \%$ ashes.

Chemical Treatment of Saccharum Sodium hydroxide was used for chemical treatment with four weight percents include $0.5,1,2$ and $2.5 \%$ at room temperature. The molarities of these solutions were prepared by dissolving certain weight of sodium hydroxide (M.wt. $40 \mathrm{gm} / \mathrm{mol}$ and purity $99 \%$ ) in $100 \mathrm{ml}$ of distilled water with volumetric flask. This treatment was achieved by immersion the short fibers in alkaline solution for $48 \mathrm{hrs}$.

Randomly oriented fibers were used to reinforce composites and added to matrix composite, and then very well mixed to maintain the uniformly distribution and finally poured in certain molds. Cast iron molds with dimensions of $(191 \times 13 \times 5 \mathrm{~mm})$ and $(80 \times 10 \times 5 \mathrm{~mm})$. Decreasing with vaseline was done for these molds were coated to avoid the adhesion of the prepared composites with inner surfaces and to easier removal of specimens. The prepared samples were left in the mould for (24) hrs. at room temperature for curing.

Thermogravimetric analysis (TGA) was carried out at University of Baghdad/college of education for pure science Ibn Al - Haitham by employing (STA PT - 1000 linseis). The temperature range was from ambient temperature to $600^{\circ} \mathrm{C}$ at heating rate of $100^{\circ} \mathrm{C} / \mathrm{min}$ under Nitrogen stream.

\section{RESULTS AND DISCUSSION}

Thermo gravimetric analysis (TGA) is a useful analytical technique to assess thermal stability of materials including polymers by recording weight loss of a sample against temperature [4]. TGA thermograms for prepared films are shown in Figures (1) to (6). Figure (1) shows the TGA curve of pure unsaturated polyester, which indicates the two decomposition steps [5] that represent the scission of highly stained portion of crosslinked unsaturated polystyrene with followed free radicals that promote the final decomposition and scission of unsaturated polyester backbone [6]. The first occurs at the range of temperatures $(230-3550 \mathrm{C})$ with weight loss of $90 \%$ while the second step occurs at temperature range of $(480-560 \mathrm{oC})$ with weight loss of $10 \%$ and that comes to $100 \%$ weight loss under the used temperature range.

The reinforced unsaturated polyester composites with untreated and treated sacchraum fibers are shown in Fig. (2) to (6). These figures show the two decomposition steps and they indicate that unsaturated polyester reinforced with untreated sugarcane and the alkali treated one with concentration of $(2.5 \%)$ fibers enhance thermal stability comparing to the pure unsaturated polyester by shifting the temperature range of first decomposition step to a higher values, decreasing the weight loss occurred at first decomposition step and decreasing the total weight loss under the temperature range used. The unsaturated polyester reinforced with treated alkali solutions with concentrations of $(0.5,1$, and $2 \%)$ never change greatly the weight loss at first and second decomposition steps comparing to pure unsaturated polyester. Moreover total weight loss is still $100 \%$ but there are some changes in temperature ranges of both first and second decomposition steps. We see that the concentration of alkali $(0.5 \%)$ shifts temperature ranges of first and second decomposition steps to a higher values comparing to pure unsaturated polyester. The unique behavior of unsaturated polyester reinforced with alkali treated sugarcane fibers of concentration $(2.5 \%)$ comparing to other treated fibers is due to lignin dissolution in highly concentrated alkali 


\section{AL-QADISIYAH JOURNAL FOR ENGINEERING SCIENCES}

Vol. 11 , No. 4

ISSN: $1998-4456$

solution which increase crystallinity of saccharum fibers [7]. Other data of thermal analysis of prepared composites are listed in Table (1).

\section{CONCLUSIONS}

The alkaline treatment of saccharum fibers to reinforce unsaturated polyester gave good incorporation of fibers in composites with slightly change of the thermal stability through the testing of thermogravimetric analysis (TGA).

\section{REFERENCES}

1. Misook Kim - Donal F. Day "Composition of sugar cane, energy cane, and sweet sorghum suitable for ethanol production at Louisiana sugar mills"J Ind Microbiol Biotechnol 2011,(33) no.7.

2. Daniela A. Mortari, Marina C. Britto, Paula M. Crnkovic," Correlation Between Activation Energy and Thermal Decomposition Yield of Sugar Cane Bagasse under CO2/O2 and N2/O2",J.of chemical engineering transactions,2014 vol.37 pp (31-36)

3. A. A. Guilherme1*, P. V. F. Dantas1, E. S. Santos1, F. A. N. Fernandes2 and G. R. Macedo1," EVALUATION OF COMPOSITION, CHARACTERIZATION AND ENZYMATIC HYDROLYSIS OF PRETREATED SUGAR CANE BAGASSE " Brazilian Journal of Chemical Engineering, Vol. 32, No. 01, pp. 23 - 33, January - March, 2015.

4. Hatakeyama T.and Quinn F.X. ,"thermal analysis fundamentals and applications to polymer science",second edition,Jhon wiley and sons ,1999

5. J.M. Ferreira,O.A.Z.Errajhi,M.O.W.Richardson,"thermogravimetric analysis of aluminized E-glass fiber reinforced unsaturated polyester composite"polymer testing,vol,25,2006,2006,pp(1091-1094).

6. Maria R Ricciardi, Vincenza Antonucci, Michele Giordano and Mauro Zarrelli,"Thermal decomposition and fire behavior of glass fiber- reinforced polyester resin composites containing phosphate-based fire-retardant additives" Journal of Fire Sciences 30(4),pp. 318-330

7. Kyaw Wunna*,a, Kiyohiko Nakasakib, Joseph L. Aureseniaa, Leonelia C. Abellaa, Pag-asa D. Gaspilloa," Effect of Alkali Pretreatment on Removal of Lignin from Sugarcane Bagasse",J.of CHEMICAL ENGINEERING TRANSACTIONS, VOL. 56, 2017,pp.(1831-1836) 
AL-QADISIYAH JOURNAL FOR ENGINEERING SCIENCES
Vol. 11 , No. 4

ISSN: $1998-4456$

Table (1) Data of TGA thermograms for prepared composites reinforced with saccharum (Sac.).

\begin{tabular}{|c|c|c|c|c|c|}
\hline \multirow[t]{2}{*}{ Sample } & \multirow{2}{*}{$\begin{array}{l}\text { Step of } \\
\text { decomposition }\end{array}$} & \multicolumn{2}{|c|}{$\begin{array}{l}\text { Temp. range } \\
\left({ }^{\circ} \mathrm{C}\right)\end{array}$} & \multicolumn{2}{|c|}{ Weight loss (\%) } \\
\hline & & Onset & Endset & Partial & Total \\
\hline Pure polyester & $\begin{array}{l}1^{\text {st }} \\
2^{\text {nd }}\end{array}$ & $\begin{array}{l}230 \\
480 \\
\end{array}$ & $\begin{array}{l}355 \\
560 \\
\end{array}$ & $\begin{array}{l}90.00 \\
10.00 \\
\end{array}$ & 100 \\
\hline $\begin{array}{l}\text { Composite with } \\
\text { untreated Sac. }\end{array}$ & $\begin{array}{l}1^{\text {st }} \\
2^{\text {nd }}\end{array}$ & $\begin{array}{l}270 \\
480 \\
\end{array}$ & $\begin{array}{l}365 \\
560 \\
\end{array}$ & $\begin{array}{l}86.00 \\
9.18 \\
\end{array}$ & 95.23 \\
\hline $\begin{array}{l}\text { Composite with } \\
\text { treated Sac. in } 0.5 \%\end{array}$ & $\begin{array}{l}1^{\text {st }} \\
2^{\text {nd }}\end{array}$ & $\begin{array}{l}280 \\
500\end{array}$ & $\begin{array}{l}375 \\
550\end{array}$ & $\begin{array}{l}92.00 \\
8.00\end{array}$ & 100 \\
\hline $\begin{array}{l}\text { Composite with } \\
\text { treated Sac. in } 1 \%\end{array}$ & $\begin{array}{l}1^{\text {st }} \\
2^{\text {nd }}\end{array}$ & $\begin{array}{l}230 \\
470 \\
\end{array}$ & $\begin{array}{l}360 \\
550 \\
\end{array}$ & $\begin{array}{l}91.00 \\
9.00 \\
\end{array}$ & 100 \\
\hline $\begin{array}{l}\text { Composite with } \\
\text { treated Sac. in } 2 \%\end{array}$ & $\begin{array}{l}1^{\text {st }} \\
2^{\text {nd }}\end{array}$ & $\begin{array}{l}220 \\
500\end{array}$ & $\begin{array}{l}360 \\
540\end{array}$ & $\begin{array}{l}88.00 \\
12.00\end{array}$ & 100 \\
\hline $\begin{array}{l}\text { Composite with } \\
\text { treated Sac. in } 2.5 \%\end{array}$ & $\begin{array}{l}1^{\text {st }} \\
2^{\text {nd }}\end{array}$ & $\begin{array}{l}250 \\
500\end{array}$ & $\begin{array}{l}360 \\
560\end{array}$ & $\begin{array}{l}83.23 \\
13.52\end{array}$ & 96.75 \\
\hline
\end{tabular}

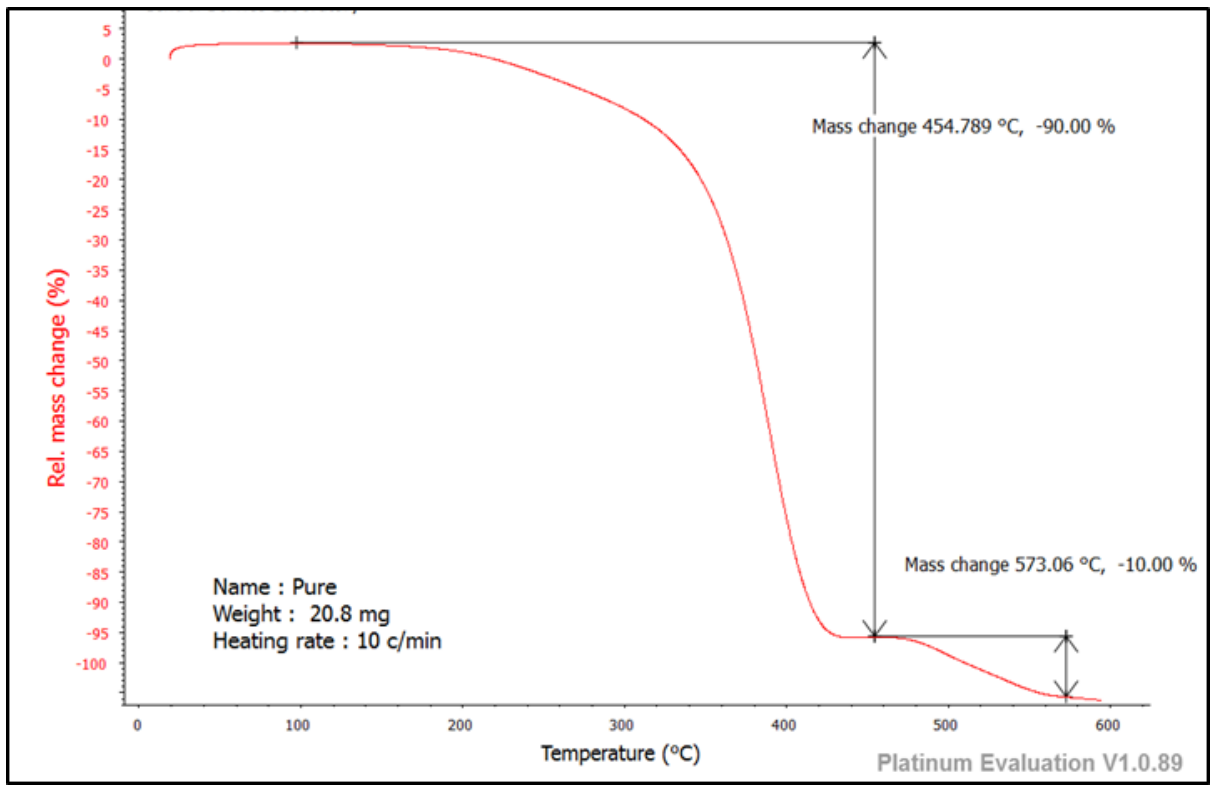

Fig. (1) TG curve of unsaturated polyester. 


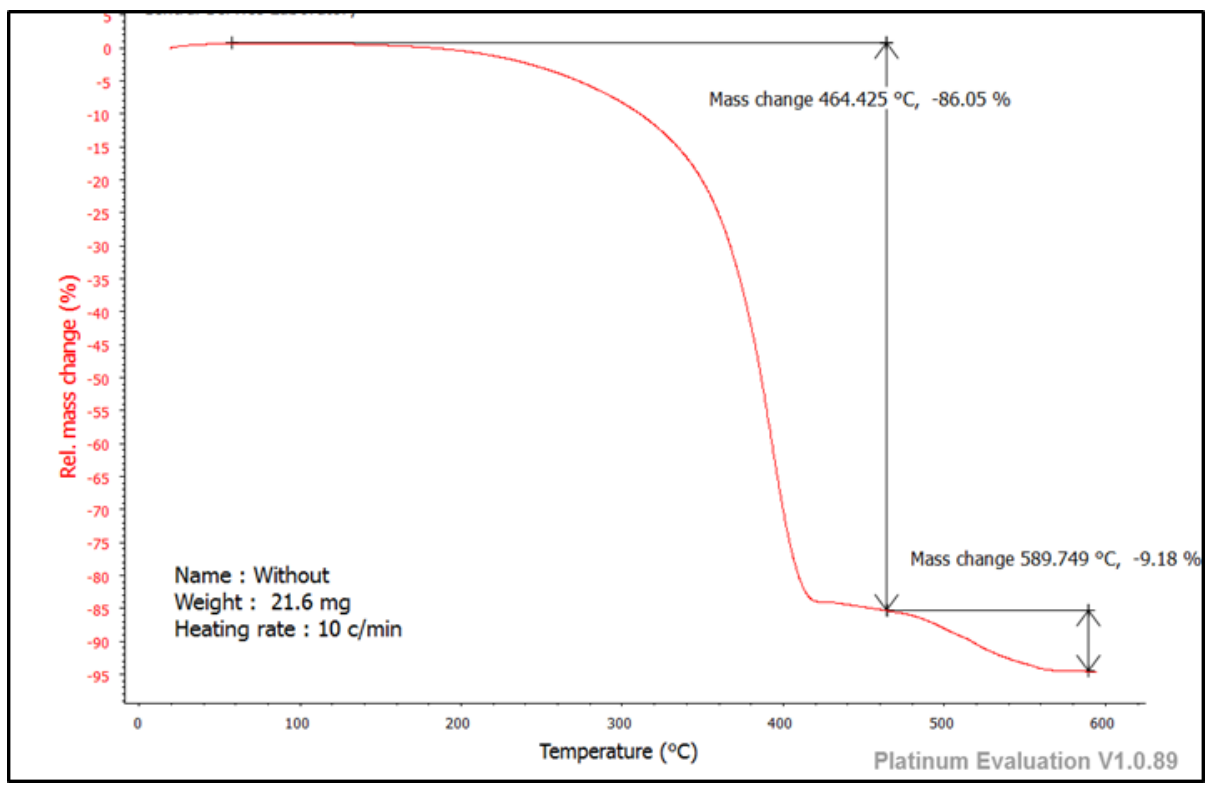

Fig. (2) TG curve of untreated saccharum/ unsaturated polyester composite.

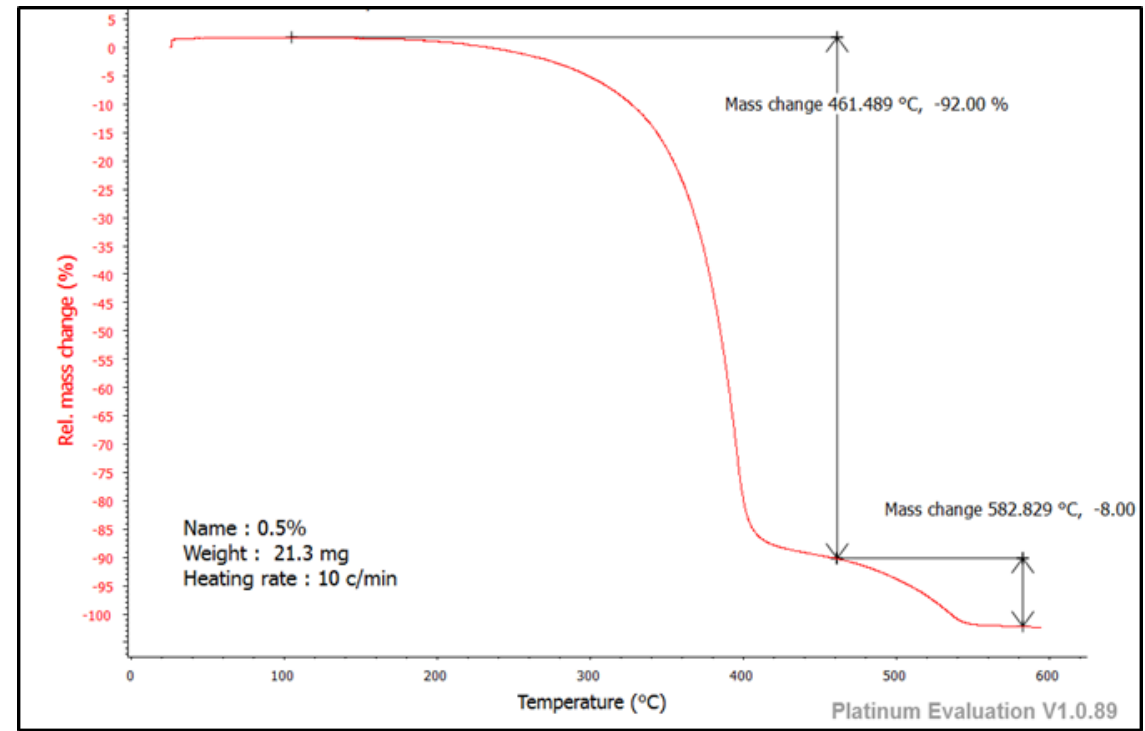

Fig. (3) TG curve of treated saccharum $(0.5 \%) /$ unsaturated polyester composite. 


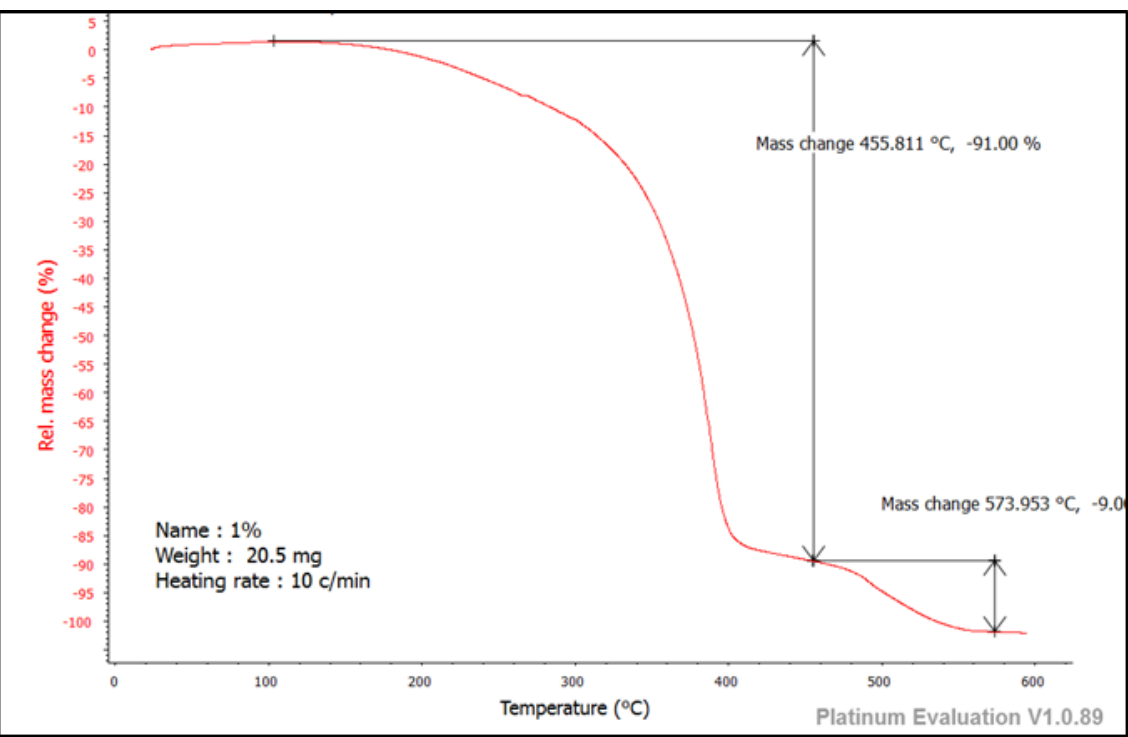

Fig. (4) TG curve of treated saccharum (1\%)/ unsaturated polyester composite.

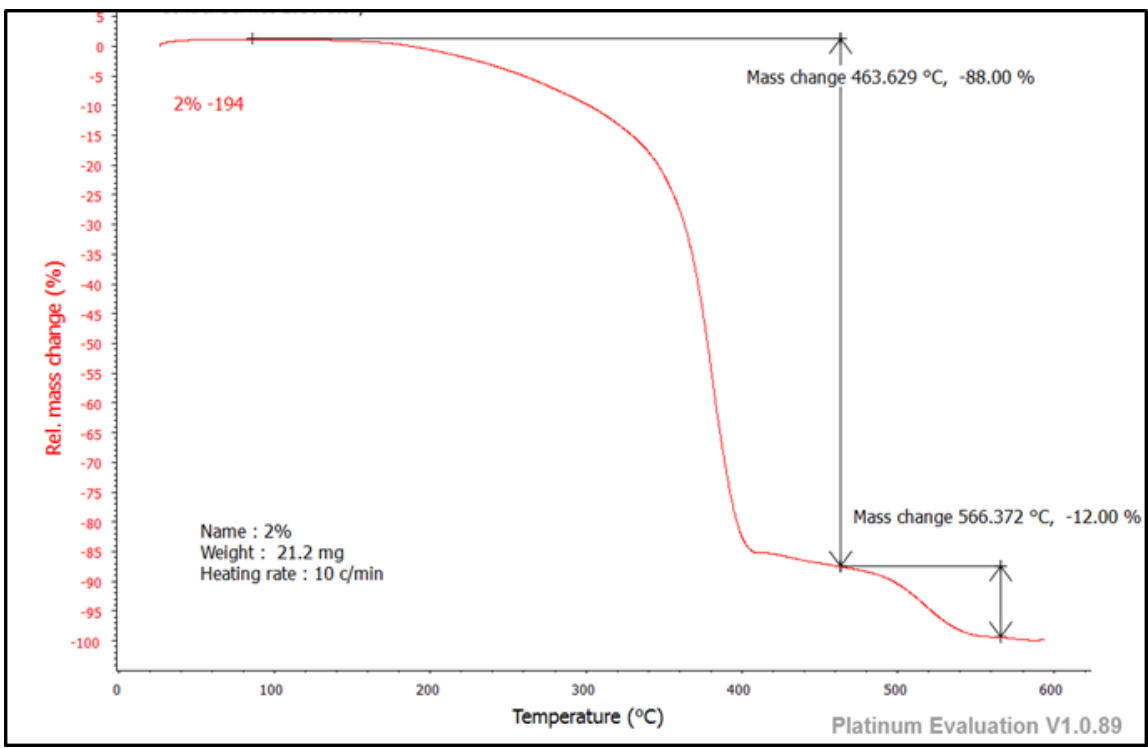

Fig. (5) TG curve of treated saccharum (2\%)/ unsaturated polyester composite. 


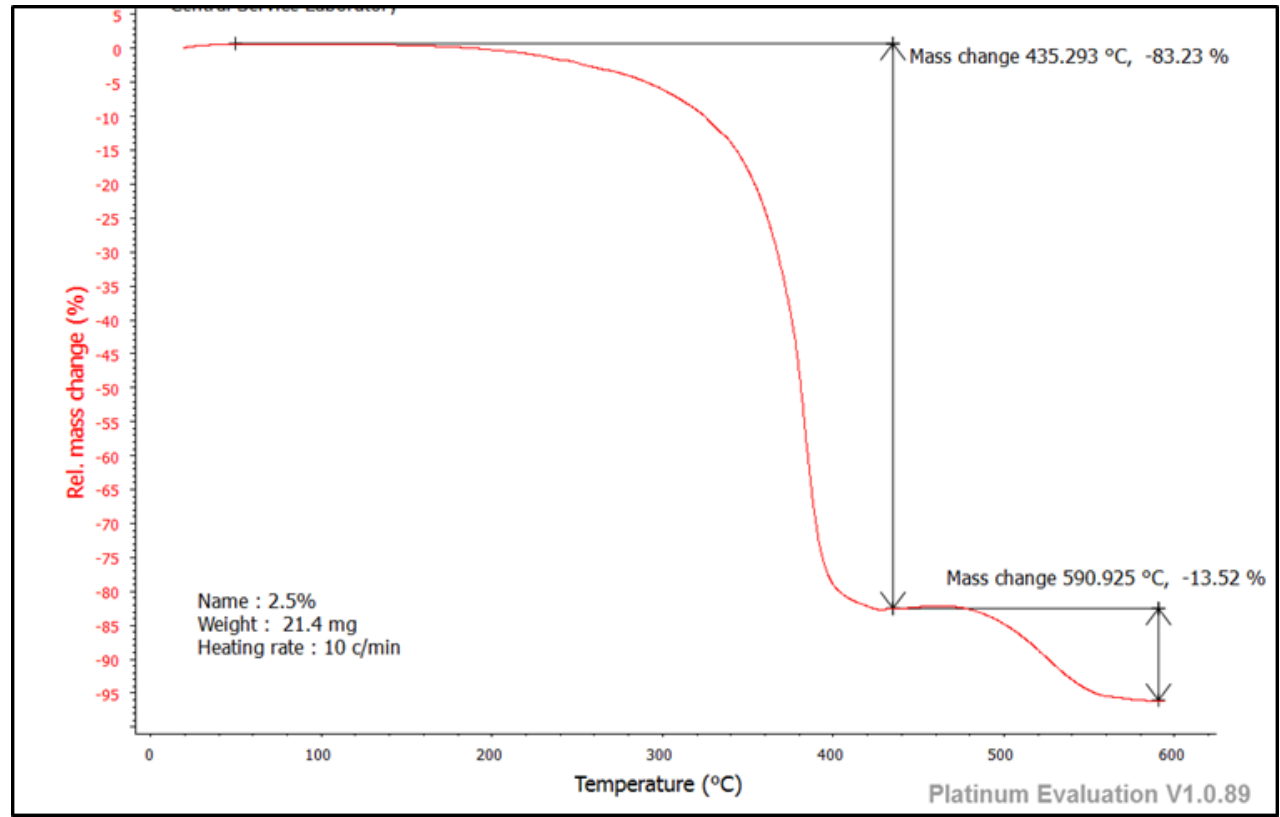

Fig. (6) TG curve of treated saccharum (2.5\%)/ unsaturated polyester composite 